DOI: $10.17516 / 1997-1370-0879$

УДК 78.072 .2

\title{
The Concept of "Genre" in the Scientific Heritage of Feodosy Rubtsov
}

\author{
Evgenia S. Redkova* \\ St. Petersburg State Rimsky-Korsakov Conservatory \\ St. Petersburg, Russian Federation
}

Received 10.10.2021, received in revised form 10.12.2021, accepted 18.01.2022

\begin{abstract}
Professor of the Leningrad State Conservatory composer Feodosy Antonovich Rubtsov (1904-1986) entered the history of Russian musicology as the author of the original concept of the structure of scales of folk songs. The scientist formulated main positions in monographs "Intonation Relations in the Songs of Slavs" (1962) and "The principles of mode construction in Russian Folk Songs" (1964). Comprehension of the concept of "genre", the definition of genre features of traditional folk songs is a littleknown side of Rubtsov's scientific heritage.

The study of archival documents (in particular, the transcripts of the report "Principles for Determining Genres of Folk Songs", which was made in 1966 at the Leningrad department of the Union of Composers at the scientific conference "Theoretical Problems of Musical Forms and Genres") shows that the scientist formulated a number of positions that were relevant for the 1960-1970. "Genre" is a genus and species concept, multi-level concept. The main criterion for determining the genre is the function, the stylistic features and the type of form are important too. Rubtsov noted that the genre system of folklore is capable of renewal, and the characteristic property of the genres of musical folklore lies in their ability in a certain context to act as a function of another genre.
\end{abstract}

Keywords: genre, genre features, musical folklore, Feodosy Rubtsov.

Research area: musical art / art history and cultural studies

Citation: Redkova, E.S. (2022). The concept of «genre» in the scientific heritage of Feodosy Rubtsov. J. Sib. Fed. Univ. Humanit. soc. sci., 15(1), 95-102. DOI: 10.17516/1997-1370-0879

(C) Siberian Federal University. All rights reserved

* Corresponding author E-mail address: akseniya.krupkina@mail.ru 


\title{
Понятие «жанр» в научном наследии Ф.А. Рубцова
}

\author{
Е.С. Редыкова \\ Санкт-Петербургская государственная консерватория \\ им. Н. А. Римского-Корсакова \\ Российская Федерачия, Санкт-Петербург
}

\begin{abstract}
Аннотация. Разработка понятия «жанр» и системы жанровых признаков малоизвестная сторона научного наследия музыковеда-фольклориста, композитора, профессора Ленинградской государственной консерватории, автора исследований «Интонационные связи в песенном творчестве славянских народов» (1962), «Основы ладового строения русской народной песни» (1964) Феодосия Антоновича Рубцова (1904-1986). Изучение стенограмм конференций (доклад «Принципы определения жанров в народной песенности»), неизданных работ «Хрестоматия по народному музыкальному творчеству (1952) и «Народные песни Смоленской области» (1969) показывает, что при исследовании жанров музыкального фольклора ученый высказал ряд актуальных для 1960-1970-х годов позиций, понимая «жанр» как родо-видовое, многоуровневое понятие, ведущим критерием определения которого является функция, а также стилевые признаки и тип художественной формы. Рубцов отмечал, что жанровая система фольклора способна к обновлению, а характерное свойство жанров музыкального фольклора заключается в их способности в определенном контексте выступать в функции другого жанра.
\end{abstract}

Ключевые слова: жанр, жанровые признаки, музыкальный фольклор, Феодосий Антонович Рубцов.

Научная специальность: музыкальное искусство / искусствоведение и культурология.

\section{Введение в проблему исследования}

Авторы посвященных анализу музыкальных форм и жанров исследований последних десятилетий (Korobova, 2012; Nazajkinskij, 2003; Rudichenko, 2004; Ruch'evskaya, 1998) особенно выделяют 1960-1970-е гг. ${ }^{1}$ В отечественном музыкознании этот период рассматривается как время пристального внимания к теоретическому обоснованию категории «жанр» и вопросам жанровой классификации. Состояние науки было таково, что изучение жанров музыкального фольклора развивалось во взаимосвязи с общим музыкознанием. Однако исследователи народной музыки наряду с разработками музыковедов в значительной мере учитывали опыт филологов в области жанровой классификации текстов фольклор-

\footnotetext{
1 В эти годы были изданы такие важные для теории жанров работы, как: Al'shvang, 1964; Zemtsovskij, 1968; Zemtsovskij, 1967; Sohor, 1971; Sohor, 1968; Tsukkerman, 1964.
}

ных произведений (большое влияние оказали труды: Propp, 1964; Kolpakova, 1962; Balashov, 1977).

\section{Постановка проблемы}

$\Phi$. А. Рубцов известен в отечественном этномузыкознании прежде всего как автор работ, посвященных ладовому строению народных песен и интонационным связям славянского мелоса. Неопубликованные труды ученого и стенограммы выступлений на конференциях демонстрируют его интерес к проблемам жанра, жанровой классификации музыкального фольклора.

В 1960-1970-е гг. Ф.А. Рубцов входил в число ведущих специалистов Ленинграда по музыкальному фольклору. Его трудовая деятельность была связана с несколькими ведущими организациями: Фонограммархивом Института русской литературы (Пушкинский Дом) РАН, Ленинградской 
государственной консерваторией имени Н.А. Римского-Корсакова, Российским институтом истории искусств (РИИИ), а также Ленинградским отделением Союза композиторов (в частности, основанной при его участии секцией музыкального фольклора). Таким образом, Ф.А. Рубцов имел возможность наблюдать, в каком ключе развивались научные школы различных учреждений, принимать непосредственное участие в обсуждении наиболее острых проблем. К числу таких чрезвычайно актуальных не только для музыкальной фольклористики, но и музыкознания в целом аспектов относилось изучение категории «жанр», жанрообразующих признаков и критериев определения жанров.

\section{Материалы}

\section{и методология исследования}

Настоящая статья опирается на архивные ранее неопубликованные документы, которые будут рассмотрены в хронологическом порядке:

- Хрестоматия по народному музыкальному творчеству. Архив Фольклорноэтнографического центра имени А. М. Мехнецова Санкт-Петербургской государственной консерватории имени Н.А. Римского-Корсакова. Рукописный фонд Ф. А. Рубцова. Папка 4. Единица хранения 07. (далее - Архив ФЭЦ СПбГК. РФ Ф. А. Рубцова. П. 4. Ед. хр. 07).

- Принципы определения жанров в народной песенности. Фонограммархив Института русской литературы (Пушкинский Дом) РАН. Рукописный фонд. Раздел 2. Фонд Ф. А. Рубцова (далее - ФА ИРЛИ. РФ. Р. 2. Ф. Ф. А. Рубцова).

- Народные песни Смоленской области. Архив ФЭЦ СПбГК. РФ Ф. А. Рубцова. П. 1. Ед. хр. 01; П. 3. Ед. хр. 04, 05; П. 4. Ед. хр. 06; П. 8. Ед. хр. 09; П. 9. Ед. хр. $10^{2}$.

В процессе работы по датировке и определению принадлежности материалов Руб-

\footnotetext{
2 В полном виде сборник не был опубликован. Предисловие, вступительная статья Ф.А. Рубцова были изданы (Marchenko, 2006). В настоящей статье учитывается раздел «Содержание», который позволяет сделать наблюдения о жанровой классификации песен и наигрышей.
}

цова сопоставлялись источники из разных архивов. Исследование документов проводилось на основе источниковедческого анализа, текстологического и сравнительноисторического методов изучения.

\section{Обсуждение}

Первые подходы к осмыслению жанра предприняты Ф.А. Рубцовым в процессе создания «Хрестоматии по народному музыкальному творчеству». Поводом для создания учебно-методической разработки стал приход Ф.А. Рубцова в 1948 году в качестве преподавателя курса «Народное музыкальное творчество» в консерваторию и отсутствие необходимых для преподавания учебников и пособий. Составление Хрестоматии заняло несколько лет (окончание работы: 1951-1952 гг.). Рукопись так и не была опубликована, но существовала во множестве машинописных копий, по которым занимались практически все ученики (музыковеды и композиторы) Ф. А. Рубцова.

В Хрестоматию вошло около ста образцов различных жанров музыкального фольклора из разных областей России (Архангельской, Вологодской, Ленинградской, Псковской, Смоленской, Орловской, Воронежской и др.), а также Белоруссии. Каждый пример сопровождается сведениями о жанровой принадлежности, особенностях исполнения, времени и месте записи.

Для Хрестоматии характерен жанровый принцип расположения материала по трем разделам:

- песни годового земледельческого круга и органически родственные им в своих истоках игровые и хороводные;

- песни, связанные с семейным бытом;

- эпические песни.

Предисловие отражает взгляд Рубцова на историю становления музыкального фольклора, его происхождение и специфику. В ходе рассмотрения этих аспектов на первый план выходит проблема жанра: «Формирование отдельных песенных жанров, или в дальнейшем разновидных “внутрижанровых” слоев, может служить своеобразными вехами, отмечающими 
важнейшие этапы в процессе развития песенной культуры, неразрывно связанной с ходом развития общественных отношений и человеческого сознания. Это естественное следствие того, что жанр в искусстве всегда исторически обусловлен художественной формой, определяющейся, прежде всего, ее общественным назначением. Именно последнее вызывает к жизни то или иное содержание, которое отбирает соответствующие средства выражения и диктует новые формы, откристаллизовавшиеся впоследствии как определенный жанровый признак. Нельзя, однако, полагать, что указанные "жанровые ступени" в развитии песенной культуры появляются последовательно и каждый вновь возникающий жанр стирает жизнеспособность предыдущего. В каждый отрезок времени мы можем наблюдать одновременное сосуществование нескольких жанров, находящихся в той или иной степени взаимопроникновения и взаимовлияния» [Архив ФЭЦ СПбГК. РФ Ф. А. Рубцова. П. 4. Ед. хр. 07. Л. 2].

В предисловии Рубцов указывает, что, поскольку в литературе специфика различных музыкальных жанров представлена недостаточно, в начале каждого раздела будет размещен краткий комментарий, который раскроет историческую обусловленность, назначение, содержание, характерный круг музыкальных и поэтических образов каждого образца [Архив ФЭЦ СПбГК. РФ Ф. А. Рубцова. П. 4. Ед. хр. 07. Л. 5]. Данные параметры можно оценить как жанровые признаки, они в разной степени подробности по отношению к различным жанрам разработаны и представлены на страницах работы.

В Хрестоматии высказаны наблюдения, касающиеся функциональной взаимозаменяемости жанров, их генезиса и изменения роли в системе музыкального фольклора. По мнению Рубцова, песни земледельческого круга, являясь древними по происхождению, с течением времени постепенно утрачивали свое практическое назначение, «давая начало некоторым ответвлениям лирики и служа первоосновой для формирования своеобразной национально-русской мелодики» [Архив ФЭЦ СПбГК. РФ Ф. А. Рубцова. П. 4. Ед. хр. 07. Л. 14]. Ладовое строение календарных песен, по мнению Рубцова, находится под влиянием контекста бытования. Например, «нейтральный» терцовый тон характерен для жнивных песен, исполненных коллективно так, как они пелись в момент своего зарождения. Жнивные песни могут выполнять «лирическую функцию», когда исполняются женщиной сольно, «для себя» [Aрхив ФЭЦ СПбГК. РФ Ф.А. Рубцова. П. 4. Ед. хр. 07. Л. 30], что может отразиться в их ладовом строении. Таким образом, жнивные песни (календарно-обрядовые по происхождению) в определенных условиях могут выполнять функции, свойственные жанру лирических песен, связанных с повествованием, выражением эмоционального состояния. Подчеркнем, что, высказываясь таким образом, Рубцов обращал внимание не только на содержание поэтических текстов, но и на содержание напевов, раскрывающееся через средства музыкальной выразительности.

Примером объединения «жанровых разновидностей» в одну область может быть вторая группа - песни семейного быта. В нее вошли свадебные песни, причитания; песни, связанные с рождением или имянаречением ребенка; колыбельные и детские, лирические песни, т. е. «не связанные обрядовой традицией с какими-либо определенными событиями трудовой или семейной жизни и не имеющие практически-целевого назначения, а служащие для выражения чувства» [Архив ФЭЦ СПбГК. РФ Ф. А. Рубцова. П. 4. Ед. хр. 07. Л. 63]. Рубцов отмечает многообразие свадебных песен, которое «является, прежде всего, результатом наличия в обряде песен различного назначения и, следовательно, различного жанрово-стилистического характера. Однако эта разнохарактерность усугубляется своеобразием местных песенных традиций, а также одновременным существованием напевов, относящихся к совершенно разным историческим слоям» [Архив ФЭЦ СПбГК. РФ Ф.А. Рубцова. П. 4. Ед. хр. 07. Л. 72]. 
Сформулированные в Хрестоматии тезисы отражают этап осмысления категории «жанр» и подходов к классификации жанров. В ряде случаев очевиден процесс становления терминологии. Тем не менее данная работа, являясь учебно-методической, отражает основные научные подходы в разработке теории жанра: трактовку понятия, признаки, генезис, связи различных жанров, которые будут развиваться и уточняться ученым в дальнейшем.

Машинописный текст выступления Ф.А. Рубцова «Принципы определения жанров в народной песенности» был выявлен в Рукописном архиве Ф.А. Рубцова ФА ИРЛИ без указания даты и конференции, на которой он был представлен. В результате работы с документами Ленинградского отделения Союза композиторов РСФСР 1960-1970-х гг. в Центральном государственном архиве литературы и искусства удалось установить, что данный текст - копия части стенограммы докладов конференции «Теоретические проблемы музыкальных форм и жанров», проходившей в Ленинграде в Союзе композиторов в 1966 г. ${ }^{3}$

В документе содержатся стенографические отчеты, включающие сообщения Л.Г. Бергер (Москва), Ю.Г. Кона (Новосибирск), Э. В. Денисова (Москва), Ф. А. Рубцова (Ленинград), а также выступления (прения) И. И. Земцовского, И. Б. Финкельштейна, В.Л. Майского, С.М. Сигитова, А. Н. Сохора, А. Г. Юсфина, М. Г. Бялика.

Конференция была довольно масштабной: кроме вышеупомянутых исследователей в ней приняли участие В.А. Цуккерман, В.П. Бобровский, Ю.Н. Холопов, А.П. Милка, Л.Г. Данько. По материалам конференции в 1971 г. вышел сборник, составленный Л.Г. Раппопортом, под общей редакцией А.Н. Сохора и Ю.Н. Холопова «Теоретические проблемы музыкальных форм и жанров», однако перечень включенных в него статей за небольшими исключе-

\footnotetext{
ЦГАЛИ СПб. Ф. 348. ОП. 1-2. Д. 1055. Стенографический отчет научной конференции на тему: «Теоретические проблемы музыкальных форм и жанров». 141 л. Выступление состоялось 12.10.1966.
}

ниями не совпадает с содержанием стенограммы 1966 г.

По неизвестным причинам сообщение Рубцова в виде статьи не вошло в публикацию. Анализ текста доклада Рубцова показывает, что в нем развиваются и уточняются те позиции в отношении категории «жанр», которые исследователь обозначил ранее на страницах Хрестоматии.

Жанр понимается довольно широко, понятие имеет многоуровневый характер. Рубцов отмечает возможность выделения поджанров и жанровых групп. При этом в качестве ведущего критерия определения жанра указывается бытовая функция. Приведем фрагменты стенограммы, которые раскрывают не только взгляды Рубцова, но и дискуссию относительно вопросов жанра.

«Жанр - род того или иного искусства, причем, как всякий род, жанр должен обладать какими-то своими характерными признаками. Жанров много <...> есть, вероятно, и поджанры, более дробное деление, но все время мы будем ... сталкиваться с какими-то группами народного искусства, обладающими своими характерными признаками.

Традиционное деление народных песен на жанры было бы очень простым и, в сущности, очень примитивным. Оно сводилось бы к тому, что песни разделяли либо по бытовым признакам - песни обрядовые или свадебные, или хороводные, либо по признакам, взятым довольно случайно, на основании того, как именовали эти песни сами исполнители, т. е. песни протяжные, голосовые, хоровые и т. д.» [ЦГАЛИ СПб. Ф. 348. Оп. 1-2. Д. 1055. Л. 90].

Далее Рубцов ставит вопрос о принципах разделения фольклорных текстов по жанрам: «Что же может служить критерием? По-моему, ответ есть один, очень четкий, очень ясный: бытовая функция песни - и ничего другого.

В чем проявляется бытовая функция песни?

Проявляется, прежде всего, в напеве. Потому что именно музыка обслуживает в данном случае текст. Текст соединяется 
с музыкой. А напев определяет сущность песни.

Приведу простой пример. Возьмем колыбельную песню. Ведь в ней можно петь, в сущности, о чем угодно. Напев всегда подскажет вам, что это песня колыбельная» [ЦГАЛИ СПб. Ф. 348. Оп. 1-2. Д. 1055. Л. 91-92].

Подводя итог, Рубцов выделяет основной признак жанра: «Итак, есть единственный критерий определения жанров: бытовая функция песен. Эта бытовая функция сказывается, прежде всего, на музыкальной функции. И, прежде всего, на принципе соединения музыки с текстом, совпадения или несовпадения смыслового, образного и т. д.» [ЦГАЛИ СПб. Ф. 348. Оп. 1-2. Д. 1055. Л. 96].

В ходе дальнейшей дискуссии А. Н. Сохором был задан вопрос, который и сегодня не утратил актуальности: как определить функции лирических песен и баллад (как повествовательных песен)? В ответе Рубцов разграничивает лирические песни и песнибаллады. В качестве баллады рассматривает песню с сюжетом «Жена мужа зарезала»: «Бытовая функция лирической песни - это эмоциональное высказывание своего отношения к окружающей действительности, вашего личного.

Повествовательная песня - это рассказ о событиях, встречающихся в быту. Тут очень приятный, очень веселый напев, когда вы его услышите - безмятежное настроение. В чем же дело? <...>.

Огромного драматизма содержание текста. Как же объяснить такой напев? А вот как. Исполнитель не выражает своего эмоционального отношения. Его отношение таково: в жизни бывает и так. Он рассказывает, а вы судите сами, это уже дело судей. Вот различие между балладой и лирической песней. В лирической песне ... ваше личное отношение» [ЦГАЛИ СПб. Ф. 348. Оп. 1-2. Д. 1055. Л. 98-99].

Рубцов высказывает несколько замечаний о поэтике лирических песен и балладных: «Русские лирические песни, как правило, сюжета в точном смысле этого слова не имеют, это отдельные сопоставления образов, не сплетающиеся в четко развивающуюся сюжетную линию. А вот в балладах обязательно они будут сплетаться» [ЦГАЛИ СПб. Ф. 348. Оп. 1-2. Д. 1055. Л. 104].

Еще одно важное суждение Рубцова касается определения жанра песен с рекрутскими и историческими сюжетами: «Рекрутские. Это тема, а не жанр. Это мое глубокое убеждение. Потому что лирическая песня может быть наполнена различным содержанием. В лирике может быть рекрутская тема $<\ldots>$.

Исторические песни могут трактоваться по-разному. Существует историческая тема. Она может быть воспринята и изложена в плане личного высказывания, как $<\ldots>$ песни о Степане Разине, и она может быть в плане, близком к былине, чисто повествовательном, как, например, отдельные песни об Иване Грозном» [ЦГАЛИ СПб. Ф. 348. Оп. 1-2. Д. 1055. Л. 101].

Отметим, что в период 1960-1970-х гг. в музыкознании активно развивались музыкально-социологические концепции, поэтому особый интерес музыковедов вызывали работы, основанные на материалах традиционных национальных музыкальных культур. Так, вполне возможно, учитывая более поздний срок выхода сборника материалов конференции, что А.Н. Сохор отразил в статье «Теория музыкальных жанров: задачи и перспективы» некоторые аспекты, обсужденные с Рубцовым во время конференции. «В последние годы фольклористы, давно уже спорящие о природе жанров народной музыки, нашли ключ к ее пониманию в функциональном подходе: различия между жанрами и отличительные особенности каждого из них объясняются прикладными функциями, а также требованиями той конкретной жизненной обстановки (труд, обряд, домашний быт и т. д.), которая их породила и в которой они постоянно (нормативно) осуществляют эти функции. Иначе говоря - практикой их общественного бытования» (Sohor, 1971: 295).

Примером понимания Рубцовым системы жанров одного областного стиля, подходов к жанровой группировке образцов музыкального фольклора является 
неопубликованный сборник «Народные песни Смоленской области», подготовленный им совместно с учениками по материалам экспедиций Ленинградской государственной консерватории 1964-1966 гг. Рубцов был автором предисловия, аналитической статьи, научно-аналитических примечаний к песням, выступал как редактор-составитель, студенты выполняли расшифровки.

Группировка песен в сборнике имеет следующий вид:

- календарные песни: 1) собственно календарные (святочные: колядки, подблюдные; масленичные; веснянки; волочебные; майские; троицкие (духовские); купальские; петровские); 2) песни периода полевых работ (сенокосные; жнивные: зажиночные, жнивные, дожиночные; толочанские);

- семейно-обрядовые песни (плачи, свадебные песни);

- лирические песни: 1) лиро-эпические (воинские; рекрутские; исторические; солдатские); 2) старые лирические песни (любовные, семейно-бытовые); 3) песни в характере баллад;

- хороводные и игровые песни: (хороводные, игровые, шуточные);

- инструментальные наигрыши.

Представленная система свидетельствует о многоуровневом подходе к жанровой классификации фольклорных текстов. При отборе образцов для сборника Рубцов руководствовался степенью их показательности для смоленских традиции. Так, например, жанры, «выпадающие из основного стиля Смоленщины, но бытующие на ее территории» (Marchenko, 2006: 168), не были включены в сборник (к ним относятся частушки, крестьянские песни- романсы и инструментальные наигрыши на гармошке).

\section{Заключение}

Суммируем позицию Рубцова, обобщив все источники:

- жанр предстает как родо-видовая категория, существует во внутрижанровых и жанрово-стилевых разновидностях;

- жанр определяется через назначение, бытовую функцию, реализуется в связи с определенной художественной формой;

- назначение жанра определяет его содержание, что в свою очередь влияет на средства выразительности и форму, они же рассматриваются как признаки жанpa;

- жанровая система традиции характеризуется многослойностью;

- жанр может менять свою исходную функцию и выступать в функции другого жанра, что во многом зависит от контекста;

- жанры могут изменяться под воздействием социальных факторов, утрачивать свою актуальность в культуре, что может стимулировать возникновение новых.

Проблемы жанра не являлись центральными для Рубцова, но в силу их актуальности как инструмента систематизации фольклорных материалов, занимаясь педагогической, исследовательской, в том числе экспедиционной работой, он был вовлечен в процесс научного осмысления этих вопросов. Изучение архивных документов свидетельствует об актуальности научных дискуссий о жанре, демонстрирует взаимовлияние специалистов разных сфер музыкознания и других гуманитарных наук и позволяет более полно представить страницы истории отечественной науки.

\section{Список литературы / References}

Al'shvang, A. A. (1964). Problemy zhanrovogo realizma: K 70-letiyu so dnya smerti A. S. Dargomyzhskogo [Problems of Genre Realism: To the 70th Anniversary from the Date of A.S. Dargomyzhsky's Death]. In Al'shvang A. A. Izbrannye sochineniya: V 2 t. [Selected works: In 2 vol.]. Ed. by G. B. Bernandt. Moscow, Publishing house «Muzyka», 1, 97-103.

Balashov, D. M. (1977). O rodovoj i vidovoj sistematizatsii fol'klora [About Generic and Specific Systematization of Folklore]. In Russkij fol'klor [Russian Folklore]. 17. Problemy «Svoda russkogo fol'klora» 
[Problems of the «Corpus of Russian Folklore»]. Ed. by. A. A. Gorelov. Leningrad, Publishing house «Nauka», 124-134.

Kolpakova, N. M. (1962). Russkaya narodnaya bytovaya pesnya [Russian Folk Common Song]. Moscow, Leningrad, Publishing house of Academy of Sciences of USSR, $284 \mathrm{p}$.

Korobova, A. G. (2012). Teoriya zhanrov v muzykal'noj nauke: Istoriya i sovremennost': issledovanie [Theory of Genres in Musical Studies: History and Modernity: Science Research]. Saarbrücken, Palmarium Academic Publishing, $160 \mathrm{p}$.

Marchenko, Y. I. (2006). F. A. Rubtsov. Materialy k sborniku «Pesni Smolenskoj oblasti». Publikatsiya Y.I. Marchenko [F. A. Rubtsov. Materials for the Collection «Songs of the Smolensk Region». Publicated by Y.I. Marchenko]. In Iz istorii russkoj fol'kloristiki [From the History of Russian Folklore], 6. SaintPetersburg, Publishing house «Nauka», 158-247.

Nazajkinskij, E. V. (2003). Stil' i zhanr v muzyke: Uchebnoe posobie dlya studentov vysshih uchebnyh zavedenij [Style and Genre in Music: A Manual for Students of Institutions of Higher Education]. Moscow, Publishing house «Vlados», $248 \mathrm{p}$.

Propp, V. Y. (1964). Zhanrovyj sostav russkogo fol'klora [Genre Composition of Russian Folklore]. In Russkaya Literatura [Russian Literature], 4, 58-77.

Ruch'evskaya, E. A. (1998). Klassicheskaya muzykal'naya forma: Uchebnik po analizu [Classical Musical Form: Analysis Tutorial]. Saint-Petersburg, Publishing house «Kompozitor-Sankt-Peterburg», 267 p.

Rudichenko, T. S. (2004). Donskaya kazach'ya pesnya v istoricheskom razvitii [Don Cossack Song in Historical Development]. Rostov-on-Don, Publishing house «Izd-vo Rostov. gos. konservatorii imeni S. V. Rahmaninova, $511 \mathrm{p}$.

Sohor, A. N. (1968). Esteticheskaya priroda zhanra v muzyke [The Aesthetic Nature of the Genre in Music]. Moscow: Publishing house «Muzyka», 103 p.

Sohor, A. N. (1971). Teoriya muzykal'nyh zhanrov: zadachi i perspektivy [Theory of Musical Genres: Tasks and Prospects]. In Teoreticheskie problemy muzykal'nyh form i zhanrov [Theoretical Problems of Musical Forms and Genres]. Moscow, Publishing house «Muzyka», 292-310.

Sohor, A. N., editor (1971). Teoreticheskie problemy muzykal'nyh form i zhanrov [Theoretical Problems of Musical Forms and Genres]. Moscow, Publishing house «Muzyka», 365 p.

Tsukkerman, V. A. (1964). Muzykal'nye zhanry i osnovy muzykal'nyh form [Musical Genres and Basics of Musical Forms]. Moscow, Publishing house «Muzyka», $159 \mathrm{~s}$.

Zemtsovskij, I. I. (1967). Russkaya protyazhnaya pesnya: Opyt issledovaniya [Russian Lyrical Song: Essay on Study]. Leningrad, Publishing house «Muzyka», 195 p.

Zemtsovskij, I. I. (1968). K sporam o zhanrah [To disputes about genres]. In Sovetskaya muzyka [Soviet Music]. 7, 104-108. 